\title{
Design of polarization-maintaining photonic crystal fibre for dispersion compensation over the $\mathrm{E}+\mathrm{S}+\mathrm{C}+\mathrm{L}$ telecom bands
}

\author{
${ }^{1}$ Md. Sharafat Ali, ${ }^{2}$ Ahmed N., ${ }^{1}$ Shahadat Hussain, ${ }^{1}$ Samiul Habib, \\ ${ }^{2}$ Aljunid S. A. and ${ }^{2}$ Ahmad R. B. \\ ${ }^{1}$ Department of Electrical \& Electronic Engineering, Rajshahi University of \\ Engineering \& Technology, Rajshahi, Bangladesh \\ ${ }^{2}$ School of Computer and Communication Engineering, University Malaysia Perlis \\ Pauh Putra Campus, 02600, Arau, Perlis, Malaysia
}

Received: 14.07 .2014

\begin{abstract}
We investigate numerically a defected-core hybrid photonic crystal fibre (H-PCF) with a circular core and a rectangular-shaped cladding, which is designed for compensation of residual dispersion over a wide wavelength range. Our simulation results testify that this $\mathrm{H}-\mathrm{PCF}$ exhibits a large negative dispersion $(-868 \mathrm{ps} /(\mathrm{nm} \mathrm{km}))$ over the $\mathrm{E}+\mathrm{S}+\mathrm{C}+\mathrm{L}$ telecommunication bands, with the relative dispersion slope perfectly matching that of a single-mode fibre at the operating wavelength $1550 \mathrm{~nm}$. The H-PCF reveals the birefringence $1.06 \times 10^{-2}$ at the operating wavelength. In order to evaluate the sensitivity of optical properties of our $\mathrm{H}-\mathrm{PCF}$, we study the effect of variations of its parameters as large as $\pm 2 \%$ from their optimal values. Due to its specific characteristics, the H-PCF suggested in this work can be considered as an excellent candidate for compensating dispersion, maintaining a single polarization in the optical fibre transmission systems, and numerous optical sensing applications.
\end{abstract}

Keywords: dispersion-compensating fibres, negative dispersion, birefringence, photonic crystal fibre, residual dispersion

PACS: 42.81.Uv, 42.55.Tv

UDC: 681.7 .068

\section{Introduction}

Photonic crystal fibres (PCFs) have a microscopic layout of air channels throughout their length, which makes a low-index cladding around a pure-silica core [1]. By varying the number and positions of the air-holes, PCFs offer great flexibility in efficiently tuning dispersion [2, 3], birefringence [4] and nonlinearity [5, 6], which would have been unfeasible with conventional step-index fibres. It is well known that controlling chromatic dispersion and confinement losses are the major issues in the optical fibre communication systems. The dispersion causes optical pulses to spread and has to be compensated in any long-distance optical data transmission systems. One way to implement this is to use dispersion-compensating fibres (DCFs) which manifest a large negative dispersion [7]. The commercial DCFs usually have the dispersion values $D$ ranging from -100 to $-300 \mathrm{ps} /(\mathrm{nm} \mathrm{km})$ [8]. To reduce their cost, one has to make the DCFs as short as possible, which can be achieved by having the negative dispersion magnitude as large as possible. Moreover, a high optical birefringence represents a parameter important for the efficient utilization of a fibre in sensing-related applications.

Several designs for single-material PCFs have been proposed in the literature, which aim at achieving a high negative dispersion coefficient and polarization-maintaining properties. So, an 
octagonal PCF has been suggested in Ref. [9]. It exhibits attractive negative-dispersion and birefringence properties, though inclusion of elliptical air-holes in the first ring implies a complex design. The octagonal PCF suggested in Ref. [10] ensures moderate negative dispersion $(-239.5 \mathrm{ps} /(\mathrm{nm} \mathrm{km}))$ and birefringence $\left(1.67 \times 10^{-2}\right)$. Another octagonal structure (see Ref. [14]) also reveals the negative dispersion of about $-588 \mathrm{ps} /(\mathrm{nm} \mathrm{km})$ and the birefringence $1.81 \times 10^{-2}$. A dual-core PCF with a highly doped internal core has been developed by Huttunen et al. [11], with the negative dispersion peak $(-59000 \mathrm{ps} /(\mathrm{nm} \mathrm{km}))$ and the effective modal area $10 \mu \mathrm{m}^{2}$. However, its structure imposes high confinement losses, while a doped core brings about notable fabrication demands. A golden spiral design has been proposed in Ref. [15], with the birefringence $1.60 \times 10^{-2}$ and the dispersion $-400 \mathrm{ps} /(\mathrm{nm} \mathrm{km})$. Furthermore, in our previous study [16] we have also suggested a PCF showing the birefringence $2.13 \times 10^{-2}$ and the dispersion $-294.1 \mathrm{ps} /(\mathrm{nm} \mathrm{km})$, thus covering the $\mathrm{E}+\mathrm{S}+\mathrm{C}+\mathrm{L}+\mathrm{U}$ bands.

In the present work we achieve the negative dispersion coefficient even higher than the characteristics reported in our previous work. Here we mainly focus on the higher negative coefficient rather than the higher birefringence. This is why we have changed the fibre design such that to achieve a higher negative chromatic dispersion. While in the work [16] we have managed to get the dispersion value $-294.1 \mathrm{ps} /(\mathrm{nm} \mathrm{km})$, thus covering the $\mathrm{E}+\mathrm{S}+\mathrm{C}+\mathrm{L}+\mathrm{U}$ bands, the new fibre designed here manifests more than twice larger negative dispersion coefficient, which allows us to cover the $\mathrm{E}+\mathrm{S}+\mathrm{C}+\mathrm{L}$ bands. As a result, we get a stronger dispersion-compensation effect over the $\mathrm{E}$ to $\mathrm{L}$ bands at a lower cost.

To be more specific, we suggest an artificial defected hybrid PCF (H-PCF) with a circular shape of a core and circular air-holes in fibre cladding, which simplifies the fabrication process. The basic advantages of this structure are its simplicity, along with higher negative dispersion much needed in high-bit-rate transmission networks. Besides of a possible use of our H-PCF as a DCF, our fibre shows a birefringence that makes it suitable for many sensing applications. Also, this fibre manifests a high nonlinearity $\left(44.14 \mathrm{~W}^{-1} \mathrm{~m}^{-1}\right)$ at the operating wavelength $1550 \mathrm{~nm}$, which makes it potentially important for a number of nonlinear applications, e.g. optical supercontinuum ones. According to our simulations, the DCF under test exhibits the negative dispersion $-868 \mathrm{ps} /(\mathrm{nm} \mathrm{km})$ over the $\mathrm{E}+\mathrm{S}+\mathrm{C}+\mathrm{L}$ telecommunication bands and the birefringence as high as $1.06 \times 10^{-2}$.

\section{Design methodology}

Fig. 1 shows a cross-sectional view of our H-PCF. The material used for both fibre core and cladding is silica surrounded by air-holes in the fibre cladding. We use five air-hole rings for a better field confinement and reducing the confinement losses (see Ref. [10]). The core consists of circularly shaped rings and so does the second ring. The other three outer rings have rectangular shapes. To gain a birefringence, the first ring is intentionally made asymmetric. As seen from Fig. 1, two air-holes in the first ring have a diameter $d_{1}$ ' which is smaller than that of the other airholes in this ring $\left(d_{1}\right)$. In this manner, we set the pitch $\Lambda$ to be equal to $0.88 \mu \mathrm{m}$, and the first ring air-hole diameters are kept at $d_{1}=0.75 \mu \mathrm{m}$ and $d_{1}{ }^{\prime}=0.3 \mu \mathrm{m}$. The third ring air-hole diameter is $d_{3}=0.6 \mu \mathrm{m}$ and all the other air-holes, apart from those associated with the first and third rings, have the diameter $d_{2}=0.9 \mu \mathrm{m}$.

The circular air-holes are constructed with the angles equal to $45^{\circ}$ with respect to one another in the first ring and $30^{\circ}$ with respect to one another in the second ring. The third ring air-holes are tuned to get the relative dispersion slope (RDS) matching that for a single-mode fibre (SMF). The 
numbers of the air-holes in the rings 1,2,3, 4 and 5 are respectively $8,12,24,32$ and 36 . Four extra air-holes, with the diameter $d_{2}$, are placed in between the second and third rings in order to obtain better confinement properties. This results in a higher air-filling ratio and a lower refractive index around the core, thereby providing stronger light confinement ability. Notice that the refractive indices of the fibre silica and the air-holes are respectively $n_{s}=1.45$ and $n_{a}=1$ at $1.55 \mu \mathrm{m}$.

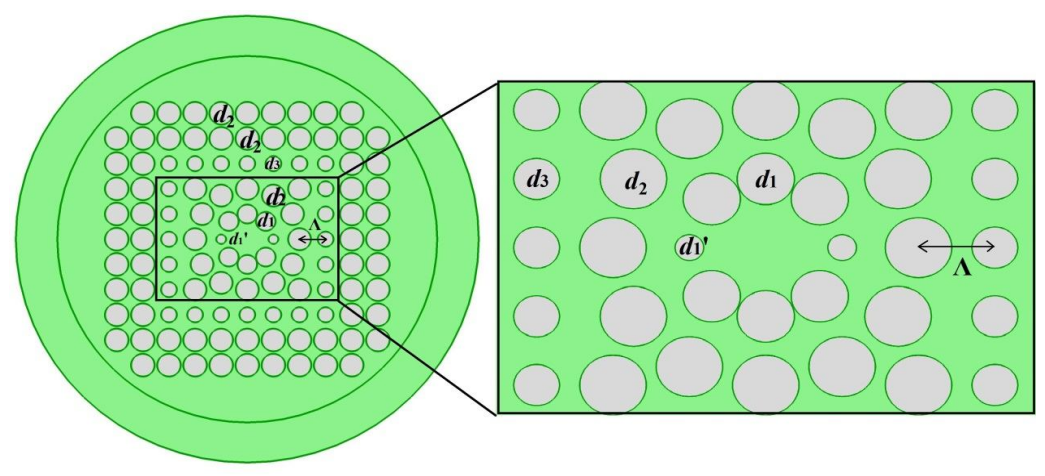

Fig. 1. Air-hole distribution in our H-PCF.

\section{Simulation technique and equations}

In our simulations, an efficient finite-element method for perfectly matched circular layers has been used for characterizing the performance of our PCF. We have used a COMSOL MULTIPHYSICS software, version 4.2, as a simulator. Once the effective modal refractive index $\eta_{\text {eff }}$ is obtained by solving the eigenvalue problem with the finite-element method, the chromatic dispersion $D(\lambda)$, the confinement loss $L c$ and the effective area $A_{\text {eff }}$ may be calculated from the Maxwell's curl equations [12] as given below:

$$
\nabla \times\left(\frac{\nabla \times E}{[s]}\right)-k_{0}^{2} \eta_{\text {eff }}^{2}[s] E=0 .
$$

Here $E$ is the electric field vector, $k_{0}=2 \pi / \lambda$ the free-space wave number, $\eta_{\text {eff }}$ the refractive index of the effective medium, $[s]$ the matrix of the matched circular layers, and $[s]^{-1}$ the inverse matrix. The effective refractive index of the base mode is given by $\eta_{\text {eff }} \beta=k$, where $\beta$ denotes the propagation constant and $k$ the wave number. Once the modal effective indices $\eta_{\text {eff }}$ are found, the dispersion $D$, the nonlinear coefficient $\gamma$, the birefringence $B$ and the confinement loss $L c$ are readily obtained using the following equations [13]:

$$
\begin{gathered}
D(\lambda)=-(\lambda / c)\left(\frac{d^{2} \operatorname{Re}\left[n_{\text {eff }}\right]}{d \lambda^{2}}\right), \\
\gamma=\left(\frac{2 \pi}{\lambda}\right)\left(\frac{n_{2}}{A_{\text {eff }}}\right) \times 10^{3} \mathrm{~W}^{-1} \mathrm{~km}^{-1}, \\
B=\left|n_{x}-n_{y}\right| .
\end{gathered}
$$

Here $\operatorname{Re}\left[\eta_{\text {eff }}\right]$ and $\operatorname{Im}\left[\eta_{\text {eff }}\right]$ mean respectively the real and imaginary parts of $\eta_{\text {eff }}, \lambda$ the 
light wavelength, and $c$ the light velocity in vacuum. The parameter $D$ in Eq. (2) corresponds to the chromatic dispersion of PCF, since the material dispersion given by the Sellmeier formula is directly included in the calculations. In Eq. (4), $n_{x}$ and $n_{y}$ are the effective refractive indices of each of the fundamental modes. Finally, $n_{2}$ in Eq. (3) stands for the nonlinear-index coefficient involved in the nonlinear part of the refractive index.

It is well understood that the long-distance optical fibre transmission systems reveal a positive dispersion and so a positive dispersion slope with the SMFs. Then the primary requirement for the DCFs designed for WDM operation is a negative and as large as possible dispersion effect. This should reduce the DCF length and, therefore, its cost. To compensate the dispersion in the SMF over some particular wavelength range, one has to satisfy the relationship (see Ref. [12])

$$
\operatorname{RDS}=\frac{S_{S M F}}{D_{S M F}(\lambda)}=\frac{S_{D C F}(\lambda)}{D_{D C F}(\lambda)},
$$

where $S_{\mathrm{SMF}}(\lambda)$ and $S_{\mathrm{DCF}}(\lambda)$ are the dispersion slopes for the SMF and DCF, respectively. The RDS for the SMF is $0.0036 \mathrm{~nm}^{-1}$. The optimal DCF should have the RDS exactly equal to that of the corresponding SMF, or at least very close to it.

\section{Simulation results and discussion}

To compensate the dispersion, high negative dispersion is needed. In its turn, the first ring must be asymmetric to provide a higher negative dispersion. Consequently, the core should be defected for obtaining higher asymmetry. Fig. 2 shows the wavelength dependences of the negative dispersion for $y$-polarized mode as calculated for different pitch parameters. At the wavelength of $1550 \mathrm{~nm}$, our structure reveals the negative dispersion coefficient as large as $-868 \mathrm{ps} /(\mathrm{nm} \mathrm{km})$ for the $y$ polarization over the $\mathrm{E}+\mathrm{S}+\mathrm{C}+\mathrm{L}$ bands.

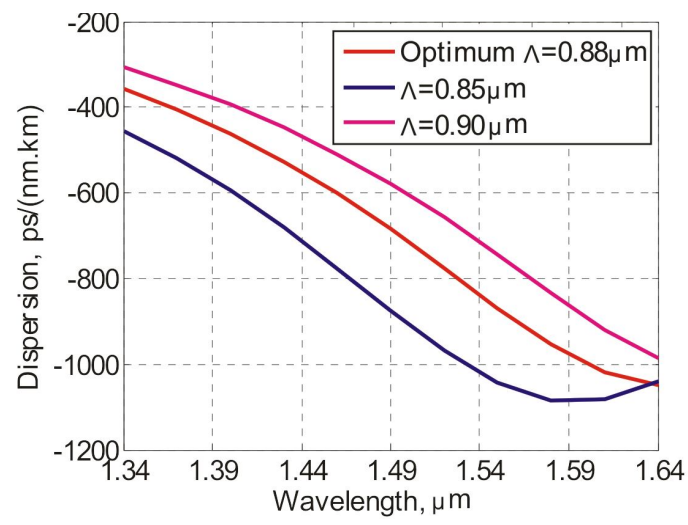

Fig. 2. Spectral dependences of negative dispersion for different pitch parameters.

Fig. 3 depicts the influence of variations in the pitch $\Lambda$ for the fibre cladding on the dispersion behaviour (here all the other parameters are kept invariable). At the operating wavelength $1550 \mathrm{~nm}$, the peak value of the negative dispersion increases with decreasing pitch. In Fig. 4 we summarize the effect of changing diameter $d_{1}$ of the first ring on the chromatic dispersion. Here all the other parameters are also kept to be constant.

In Fig. 5 we demonstrate how the changing diameter $d_{2}$ affects the chromatic dispersion. Here all of the data is gathered, which corresponds to the influence of diameters $d_{1}$ and $d_{2}$ varying in the range from \pm 1 to $\pm 2 \%$. The simulation results testify that the peak value of the negative chromatic dispersion increases with increasing $d_{1}$ and decreasing $d_{2}$. 


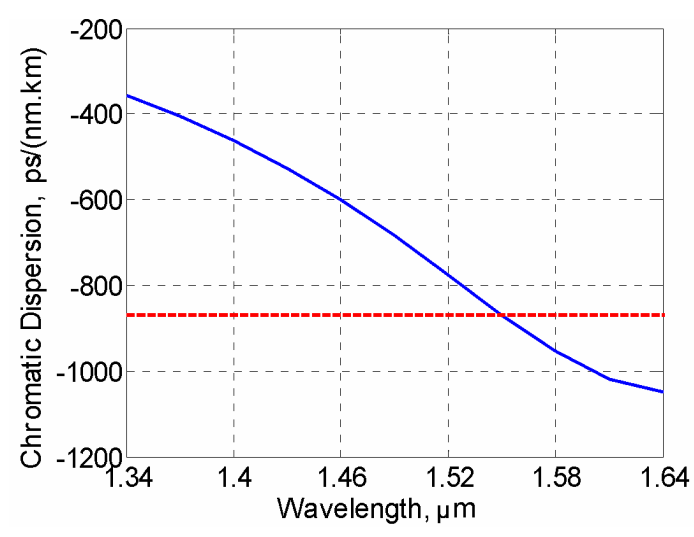

Fig. 3. Effect of pitch variation on the negative chromatic dispersion.

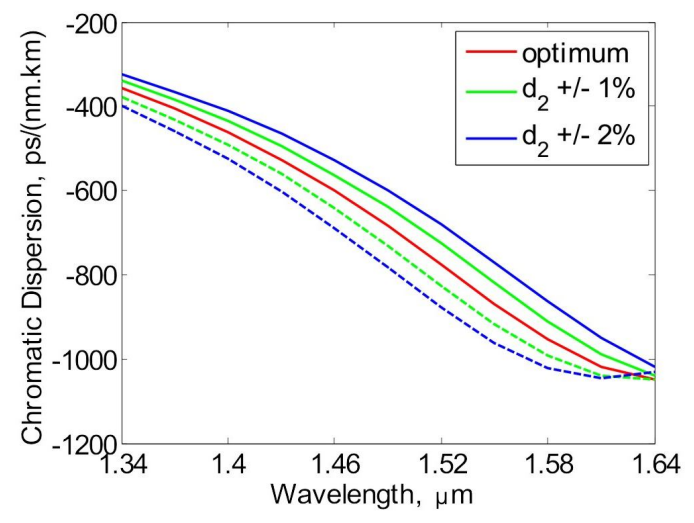

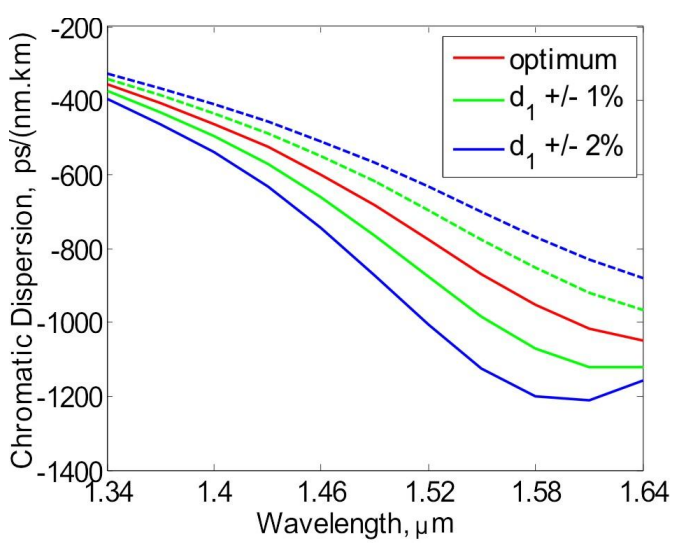

Fig. 4. Effect of variations in the first ring diameter $d_{1}$ on the negative chromatic dispersion.

Fig. 5. Effect of variations in the diameter $d_{2}$ on the negative chromatic dispersion.

Fig. 6 displays the spatial distributions of the optical fields for the $x$-and $y$-polarized modes, which are simulated for the same operating wavelength. According to our data, the fundamental optical field distributions for the both $x$ - and $y$-polarized modes are strongly linked in the highcentral core. From Fig. 7 it is easily seen that the first-order $y$-polarized mode has the higher effective index than that of the relevant $x$-polarized mode. Fig. 8 displays the birefringence dispersion for our DCF. Notice that the birefringence value under optimal conditions is equal to $1.06 \times 10^{-2}$ at the operating wavelength.
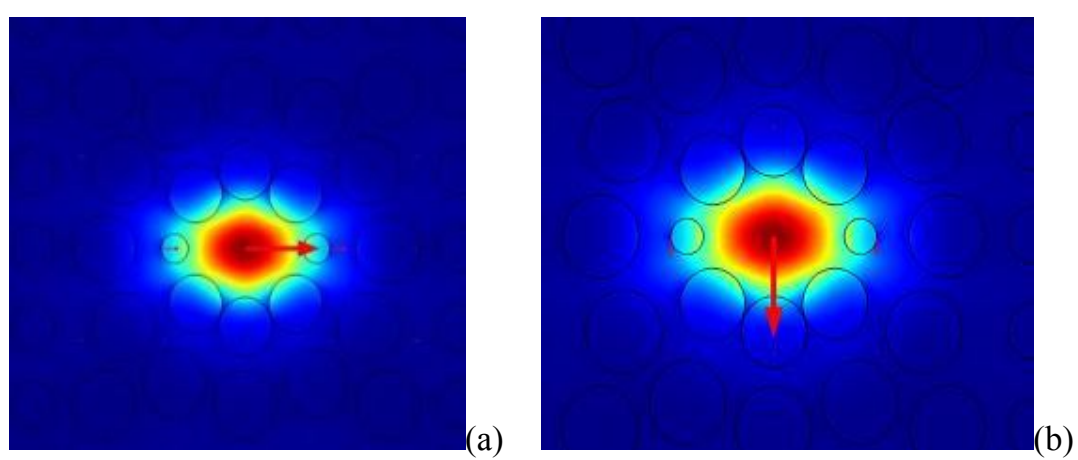

Fig. 6. Optical field distributions for (a) $x$ - and (b) $y$-polarizations.

Ukr. J. Phys. Opt. 2014, Volume 15, Issue 4 

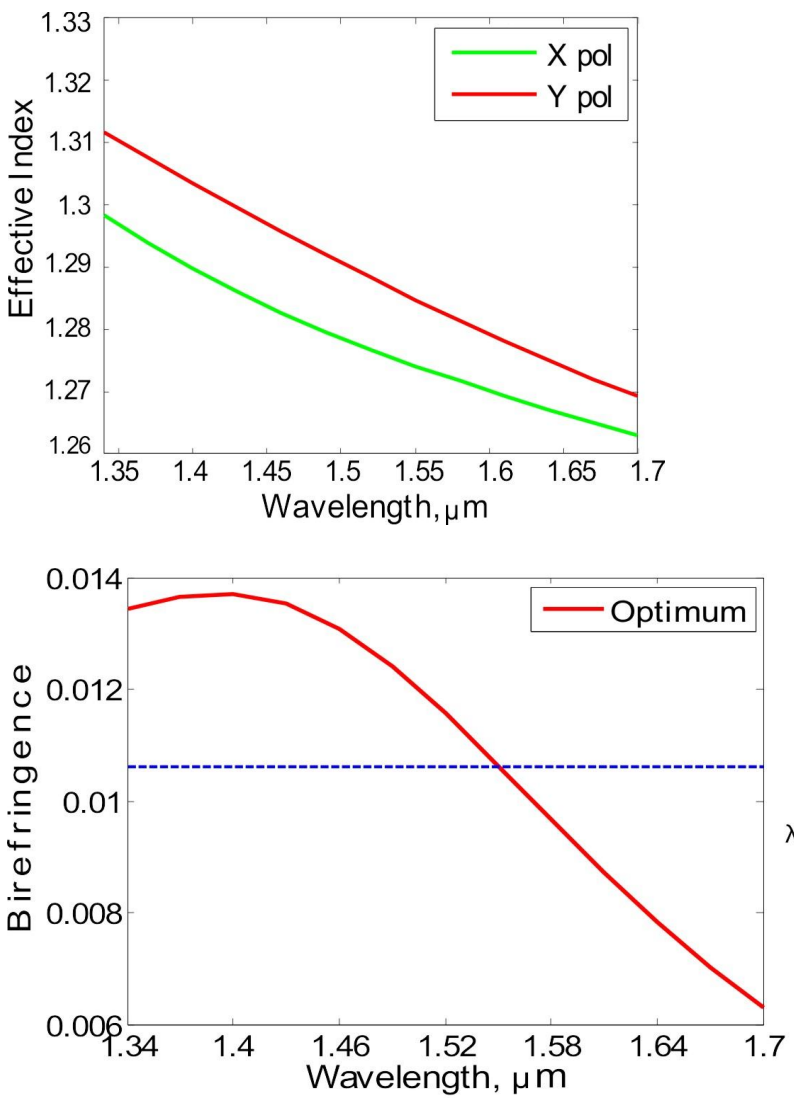

Fig. 7. Dispersion curves for the effective refractive index as simulated for $x$ - and $y$ polarizations.

The effect of changing diameter $d_{1}$ of the first ring on the birefringence dispersion is shown in Fig. 9, again under the conditions that the remaining parameters are kept optimal. The simulation reveals that the $d_{1}$ variations change significantly the slope of the curves in the region 1370-1460 nm. At the operating wavelength, the increase in $d_{1}$ decreases the birefringence value. On the other hand, the increase in the diameter $d_{2}$ increases the birefringence (see Fig. 10).

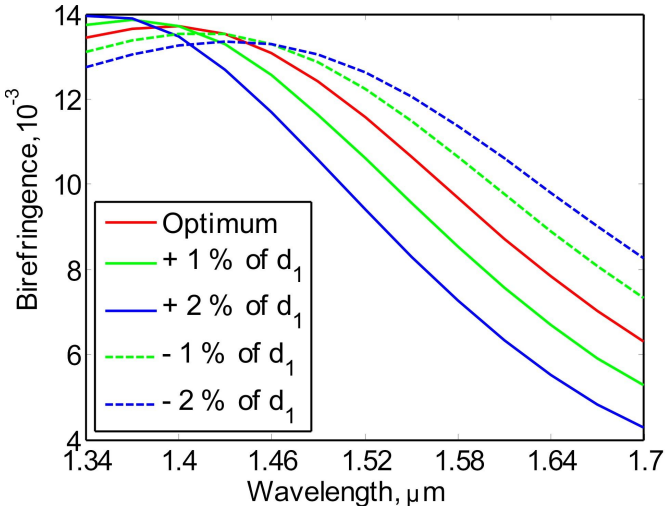

Fig. 9. Effect of variations in the first ring diameter $d_{1}$ on the birefringence dispersion.

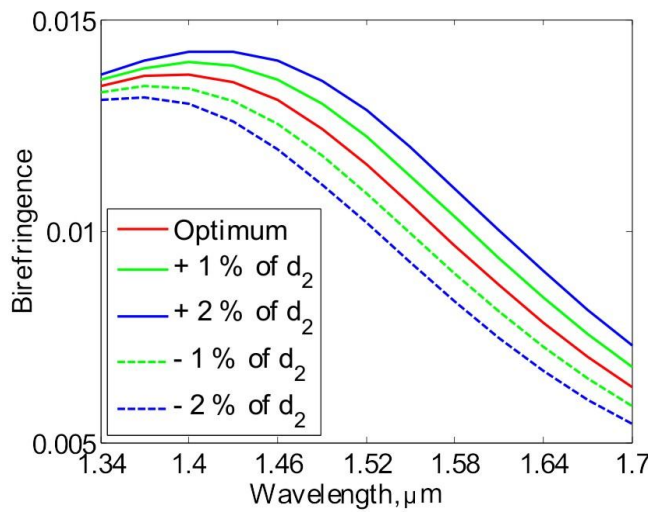

Fig. 10. Effect of variations in the diameter $d_{2}$ on the birefringence dispersion.

The effect of pitch variations is simulated in Fig. 11. As seen from Fig. 11, increasing pitch $\Lambda$ increases the birefringence and the slope changes rapidly in the region 1370-1430 nm. Fig. 12 shows the dispersion of the effective area of fibre, with the optimal parameter being $2.114 \mu \mathrm{m}^{2}$. 
This is smaller if compared to that of conventional fibres. The PCFs with a high negative dispersion have relatively small effective areas and so they would be useful for some nonlinear applications (e.g., super-continuum generation and soliton pulse transmission).
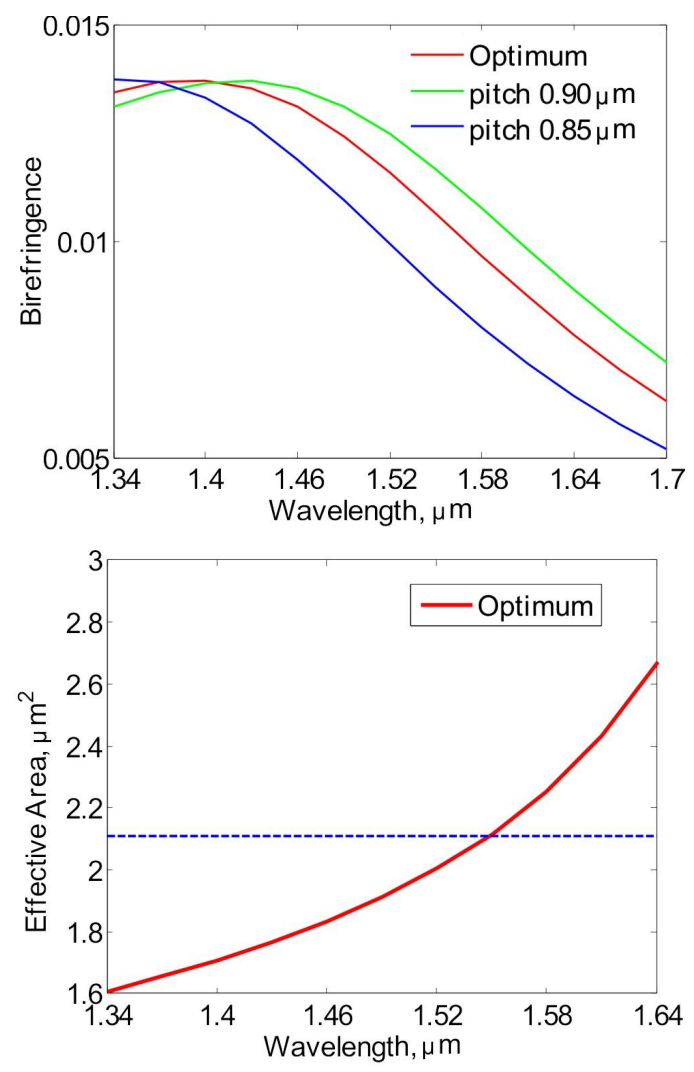

Fig. 11. Effect of pitch variations on the birefringence dispersion.

Fig. 12. Dispersion of effective area under optimal conditions.

In order to build a broadband DCF, it is necessary that the RDS of the dispersion curve be close to that of the SMF at the operating wavelength. Therefore we tune the diameters $d_{2}$ and $d_{3}$ such that to match the relevant slope (see Table 1). For the aim of optimal design, the RDS of our PCF should exactly equal to $0.0036 \mathrm{~nm}^{-1}$. Fig. 13 displays the wavelength dependence of the residual dispersion for our PCF calculated for the case of optimal design parameters. Evidently, our DCF can function in the wide telecommunication band $\mathrm{E}+\mathrm{S}+\mathrm{C}+\mathrm{L}$. This enables reliable operation in high-bit-rate telecommunication networks.

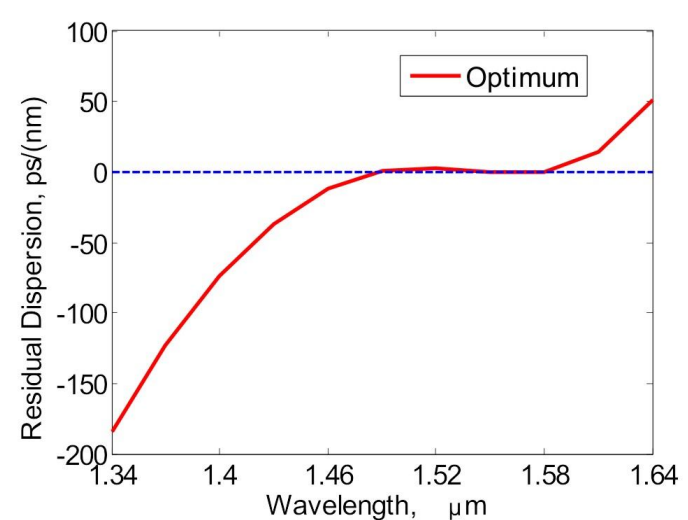

Fig. 13. Residual dispersion under optimal conditions. 
Finally, we compare the properties of our PCF with those of some other fibres designed earlier for compensating dispersion and birefringence. In particular, Table 2 concentrates on comparison of the negative dispersion and the birefringence values.

Table 1. RDS matching performed via tuning the diameters of the second and third rings.

\begin{tabular}{|c|c|c|}
\hline Diameter $d_{3}, \mu \mathrm{m}$ & Diameter $d_{2}, \mu \mathrm{m}$ & RDS, $\mathrm{nm}^{-1}$ \\
\hline 0.66 & 0.70 & 0.00275 \\
\hline 0.65 & 0.75 & 0.0032 \\
\hline 0.60 & 0.80 & 0.00351 \\
\hline 0.60 & 0.90 & 0.0036 \\
\hline
\end{tabular}

Table 2. Comparison of some parameters of our PCF and the PCFs reported earlier in the literature.

\begin{tabular}{|c|c|c|}
\hline PCF & $B=\left|n_{x}-n_{y}\right|, 10^{-2}$ & $D(\lambda), \mathrm{ps} /(\mathrm{nm} \mathrm{km})$ \\
\hline Ref. [10] & 1.67 & 239.5 \\
\hline Ref. [14] & 1.81 & 588 \\
\hline Ref. [15] & 1.60 & -400 \\
\hline Ref. [16] & 2.13 & 294.1 \\
\hline Our DCF & 1.06 & -868 \\
\hline
\end{tabular}

\section{Conclusion}

In the present study, an artificial defected H-PCF structure with a circular core is suggested. We argue that this PCF enables one to achieve a large negative dispersion coefficient ($868 \mathrm{ps} /(\mathrm{nm} \mathrm{km}))$ over the communication bands $\mathrm{E}+\mathrm{S}+\mathrm{C}+\mathrm{L}$ and a high enough birefringence $\left(1.06 \times 10^{-2}\right)$. We conclude that the characteristics of our PCF allow for its efficient utilization in high-bit-rate transmission networks and fibre sensing. The design of our H-PCF could prove to be easier and more efficient, when compared with the prototypes, because of relatively small number of geometrical parameters involved and a simple cladding structure. This also simplifies the necessary optimization procedures.

\section{References}

1. Knight J C, 2003. Photonic crystal fibers. Nature. 424: 847-851.

2. Razzak S M A and Namihira Y, 2008. Proposal for highly nonlinear dispersion-flattened octagonal photonic crystal fibers. IEEE Photon. Technol. Lett. 20: 249-251.

3. Saitoh K, Koshiba M, Hasegawa T and Sasaoka E, 2003. Chromatic dispersion control in photonic crystal fibers: application to ultra-flattened dispersion. Opt. Exp. 11: 843-852.

4. Ju J, Jin W and Demokan M S, 2003. Properties of a highly birefringent photonic crystal fiber. IEEE Photon. Technol. Lett. 15: 1375-1377.

5. Knight J C, Birk T A, Russell P J S and Sandro J P, 1998. Properties of photonic crystal fiber and the effective index model. J. Opt. Soc. Amer. A 15: 748-752.

6. Matsui T, Zhou J, Nakajima K and Sankawa I, 2005. Dispersion-flattened photonic crystal fiber with large effective area and low confinement loss. J. Lightwave Technol. 23: 41784183.

7. M Koshiba and K Saitoh, 2003. Structural dependence of effective area and mode field diameter for holey fibers. Opt. Express. 11: 1746-1756.

8. Ali M S,Nasim K M, Ahmad R, Khan M A G and Habib M S, 2013. A defected core highly 
birefringent dispersion compensating photonic crystal fiber. Proc. Intern. Conf. on Advances in Electrical Engineering (ICAEE), 100-105.

9. Selim Habib M, Samiul Habib M, Razzak S M A, Namihira Y, Hossain M A and Khan M A G, 2012. Broadband dispersion compensation of conventional single mode fibers using microstructure optical fibers. Optik. 124: 3851-3855.

10. Kaijage S F, Namihira Y, Hai N H, Begum F, Razzak S M A, Kinjo T, Miyagi K and Zou N, 2009. Broadband dispersion compensating octagonal photonic crystal fiber for optical communication applications. Jap. J. Appl. Phys. 48: 052401-052408.

11. Huttunen A and Torma P, 2005. Optimization of dual-core and microstructure fiber geometries for dispersion compensation and large mode area. Opt. Express. 13: 627-635.

12. Saitoh K and Koshiba M, 2002. Full-vectorial imaginary-distance beam propagation method based on a finite element scheme: Application to photonic crystal fibers. IEEE J. Quant. Electron. 38: 927-933.

13. Razzak S M A, Namihira Y, Begum F, Kaijage S, Hai N H and Zou N, 2007. Design of a decagonal photonic crystal fiber with ultra-flattened chromatic dispersion. IEICE Trans. Electron. E90-C: 2141-2145.

14. Selim Habib M, Samiul Habib M, Abdur Razzak S M and M Anwar Hossain, 2013. Proposal for highly birefringent broadband dispersion compensating octagonal photonic crystal fiber. Opt. Fiber Technol. 19: 461-467.

15. Arti Agrawal, Kejalakshmy N, Chen J, Rahman B M A and Grattan K T V, 2008. Golden spiral photonic crystal fiber: polarization and dispersion properties. Opt. Lett. 33: 2716-2718.

16. Md Selim Habib, Md Shohel Rana, Md Moniruzzaman, Md Sharafat Ali and N Ahmed, 2014. Highly birefringent broadband dispersion compensating photonic crystal fiber over the $\mathrm{E}+\mathrm{S}+\mathrm{C}+\mathrm{L}+\mathrm{U}$ wavelength bands. Opt. Fiber Technol. 20: 527-532.

Md. Sharafat Ali, Ahmed N., Shahadat Hussain, Samiul Habib, Aljunid S. A. and Ahmad R. B. 2014. Design of polarization-maintaining photonic crystal fibre for dispersion compensation over the $\mathrm{E}+\mathrm{S}+\mathrm{C}+\mathrm{L}$ telecom bands. Ukr.J.Phys.Opt. 15:207 - 215.

Анотація. У роботі чисельно досліджено гібридне волокно на фотонному кристалі (ГВФК) із дефектною сериевиною. Г-ВФК має круглу сериевину та оболонку прямокутної форми для компенсування залишкової дисперсї в широкому діапазоні довжин хвиль. Результати наших розрахунків засвідчують, що запропоноване Г-ВФК виявляє негативну дисперсію (-868 nc/(нм км)) у телекомунікаційних смугах $E+S+C+L$, а відносний нахил його дисперсійної кривої досконало погоджений із відповідною характеристикою одномодового волокна на робочій довжині хвилі 1550 нм. Г-ВФК виявляє подвійне заломлення $1,06 \times 10^{-2}$ на цій робочій довжині хвилі. 3 метою оцінки чутливості оптичних властивостей Г-ВФК ми вивчили вплив відхилень його робочих параметрів у межах $\pm 2 \%$ од оптимальних значень. Завдяки своїм характеристикам, запропоноване в иій роботі волокно може виявитися перспективним для компенсаиї̈ дисперсії, утримання єдиної поляризаиії світла у волоконнооптичних передавальних системах $i$ численних практичних застосувань в оптичній сенсориці. 